\title{
Certificación y acreditación en Chile: Un modelo sui generis
}

\author{
Board certification and accreditation in Chile
}

\begin{abstract}
Aunque estos dos términos se utilizan a menudo en forma indistinta, debemos hacer una clara distinción entre ellos, lo que permitirá una mejor comprensión de los procesos y los avances logrados en nuestro país en materia de certificación y acreditación. En general, es correcto aplicar el concepto de certificación a las personas ("certificación de especialista en cirugia") y reservar el concepto de acreditación para referirse a las Instituciones que cumplen una función asistencial y a los Centros encargados de la Formación Médica.
\end{abstract}

La certificación de los médicos especialistas ha estado durante más de 50 años bajo la tuición de las Universidades que eran los centro formadores a través de Programas de Especialización Específicos. El año 1984 se crea el CONACEM -Corporación Nacional Autónoma de Certificación de Especialidades Médicas - como una entidad de carácter autónomo e independiente, que se ha encargado de certificar a los médicos que en forma voluntaria lo soliciten. Los postulantes pueden ser médicos titulados en los programas de formación de especialistas debidamente acreditados de una Facultad perteneciente a ASOFAMECH, aquellos formados en el extranjero y los nacionales cuya formación surge como adiestramiento en práctica (los cuales deben rendir un examen de idoneidad). El Directorio de esta entidad está formada por 4 representantes de ASOFAMECH, 4 miembros de las Sociedades Científicas agrupadas en ASOCIMED, 4 representantes del Colegio Médico de Chile y 1 miembro de la Academia de Medicina. Se agrega 1 representante del Ministerio de Salud como observador y el Secretario Ejecutivo, ambos sin derecho a voto. A la fecha más de 10.000 médicos se han certificado en CONACEM en 50 especialidades médicas y/o en las especialidades derivadas. Los centros de atención privados, habitualmente asociados a una ISAPRE, cada vez con más fuerza exigen la certificación respectiva para contratar los médicos del staff y las Clínicas Privadas lo requieren para autorizar una intervención quirúrgica en sus dependencias en un legitimo derecho de defensa frente a la responsabilidad legal implícita. Curiosamente, en el ámbito de la Salud Pública, tal regulación es errática y dependiente de la autoridad local. De este modo, es fácil comprobar que los Servicios de Salud, en un intento de dotar a sus hospitales de especialistas, contratan médicos que no cumplieron con los requisitos mínimos, no terminaron su formación estándar, no han cumplido con el adiestramiento en práctica y no pueden cumplir con las exigencias básicas de CONACEM. Por otra parte, no es raro apreciar en los llamados a concurso que aparecen en la prensa, el requisito de certificación universitaria o de CONACEM entre los antecedentes solicitados. La nueva ley de Autoridad Sanitaria hasta ahora no ha definido el rol exacto de CONACEM ni de las Universidades como organismo de certificación en el nuevo modelo de Salud producto de la Reforma de Salud. A pesar de estas indefiniciones, CONACEM va a cumplir 25 años y ha iniciado una nueva etapa en su trayectoria durante este año al impulsar el proceso de la re-certificación. Con ello se pretende conocer la vigencia del especialista, cautelando la calidad de la práctica quirúrgica, labor que la Sociedad de Cirujanos de Chile apoya en forma entusiasta.

En forma paralela, al alero de la Ley $n^{\circ} 20.129$ sobre el Aseguramiento de la calidad de la Educación Superior promulgada el año 2006, se crea la Comisión Nacional de Acreditación (CNA), organismo público y autónomo que deberá autorizar a las Agencias Acreditadoras de Centros y Programa, además de vigilar su funcionamiento en el área de pregrado, postgrado y post-título. Nuevamente la Academia de Medicina, interesada en el problema de las Especialidades Médicas en Chile, invita en el 2005 a ASOFAMECH, ASOCIMED, Colegio Médico y otras instituciones relacionadas a participar en un proceso de estudio y estructuración de un sistema de acreditación de centros formadores. Tras un largo estudio, en Julio de 2007 se crea la Agencia Acreditadora de Programa y Centros Formadores de 
Especialistas Médicos (APICE) con representantes de ASOFAMECH, ASOCIMED, Colegio Médico de Chile y la Academia de Medicina del Instituto de Chile, que recién ha obtenido la personalidad juridica. El paso siguiente será postular para obtener la autorización de la CNA como agencia acreditadora. APICE, en cuyo directorio están representados las principales Instituciones que han dado muestras claras de transparencia y probidad en CONACEM, podría constituir un hito en la Acreditación de Centros Formadores de nuestro país, como lo ha sido CONACEM en la certificación (y pronto en la recertificación) de los especialistas médicos en Chile.

Dr. Guillermo Bannura C. Presidente de la Sociedad de Cirujanos de Chile. Santiago, Diciembre de 2008 